\title{
Saudação ao Paraninfo
}

\section{Luiz Eulalio Bueno Vidigal'}

\author{
Exmo. Sr. Diretor da Faculdade de Direito, \\ Douta Congregaçầo, \\ Exmos. Srs. Secretarios de Estado, \\ Exmos. Srs. Representantes das Congregaçōes das Escolas \\ Superiores, do Instituto da Ordem dos Advogados e da \\ Associaçầo dos Antigos Alunos da Faculdade de Direito. \\ Exmas. Senhoras, \\ Meus Senhores, \\ Colegas.
}

Em uma pagina de deliciosa ironia, divino pensador e estilista francês observa maldosamente que se não deve confiar demais no raciocinio, pois que uma argumentação solida e cuidadosa jamais provaria senão a habilidade do espirito que a conduziu: e acrescenta que, certamente, os homens suspeitam essa verdade, pois obedecem sempre, de preferencia, ás suas paixões e é raro que se deixem levar pela inteligência; acorrem pressurosos ao apêlo das religiões e quedam-se indiferentes diante das correntes filosoficas; triumfam garbosamente nas operações instintivas e fracassam fragorosamente nas operações do espirito.

A quem duvidasse dessa verdade, bastaria lembrar o caso daquela douta cainita que, alarmada com as imperfeições da creação, aconselhava a seus discipulos que infringissem as leis. 
do universo e tivessem, por bandeira, a vida de Caim e a vida de Judas. O raciocinio é, talvez, perfeito; a conclusão é abominavel. E' que, como sentia Carlyle, si é bem certo que a "moral do individuo é a equivalencia do seu entendimento", não o é menos que é preciso balanceá-lo com os juizos que nos dita o coração.

$\mathrm{Si}$, neste momento, eu pensasse friamente no que vos deveria dizer, seguramente chegaria á conclusão de que numa solenidade de formatura de bachareis, não deveria eu afastar-me do ponto de vista mais geral, evitando, cuidadosamente, quaisquer assuntos que, pela sua atualidade, pudessem atingir aos que me ouvem, ferindo as sucetibilidades dos mais sensiveis.

Falar-vos-ia, por exemplo, como que a relembrar as lições aqui recebidas, da unificação do direito privado, ou do fundamento do direito de punir: preocupado ante a perspetiva sombria de nossa vida futura, desdobraria, diante de vós, os diversos departamentos em que a nossa atividade pudesse se exercer e dissertaria sôbre os deveres e norma de conduta a que estivessemos obrigados; por outro lado, impressionado com a desordem do mundo contemporaneo, procuraria apontar os remedios para a salvação da ordem social ameaçada e atribuiria, pomposamente, importante papel á nossa geração, na luta pela detesa da civilização que nos viu nascer; e eu teria cumprido a minha missão.

Confesso, entretanto, vexado, que tamanha isenção de ânimo vái muito alêm da minha misera contingencia humana; não fui capaz de permanecer inflexivél no dominio das idéas gerais. A paixão arrastou-me. Inclinei-me á força irresistivel do sentimento de nacionalidade. Certo, perdoar-me-eis, si nesta hora, volvo os olhos ansiosos para a nossa terra e a nossa gente; permiti, que a esta e áquela, sejam dedicados os nossos últimos instantes de convivio academico.

Não foi, com certeza, para nós, que Lamennais, em uma de suas passagens de sabor biblico, afirmou envolverem-se todas as origens em obscuridade profunda. A nossa não se perde na 
noite dos tempos e não seria temerario um ensaio sôbre a nossa formação. O çaráter milagroso de que ela se revestiu não passará despercebido a quem quer que observe atentamente a nossa história. Daí, muito provavelmente, nos teria vindo esse messianismo invencivel, que tem acompanhado o evolver da nacionalidade e do qual até hoje não nos libertámos. A fatalidade nos fez indiferentes. Acostumámo-nos, desde muito cedo, a não reagir contra os obstaculos que nos assaltaram. Experiencia de quatro seculos nos ensinou a presenciar inertes e maravilhados a solução feliz e quasi espontanea que tiveram os nossos grandes problemas nacionais.

Três grandes milagres, nos quais alguns autores viram entusiasmados a generosa prodigalidade da Divina Providencia para com um povo eleito, incutiram, na alma popular, a crênça inabalavel na salvação infalivel e sobrenatural do país em seus momentos de perigo.

$\mathrm{O}$ primeiro aproveitou a Mãe Patria.

Ao espirito aventureiro português foi facil tarefa a descoberta e a conquista da terra. Dificilima, si não impossivel, havia de ser a de conservar a imensidão do territorio.

$\mathrm{Si}$ empolgavam o seu temperamento arrebatado o fulgor da conquista e a fascinação do imprevisto, contrariava-o em sua essencia, o trabalho con'tinuado e obscuro da colonização e povoamento, cujos efeitos seriam sensiveis apenas ao observador de alguns seculos. Mas, a despeito do clima adverso, da cubiça do estrangeiı e do désamparo em que se deixava a colonia, formou-se aqui o ambiente lusitano, iniludivel e patente no ardor com que o gentio colaborou na obra do português, rechassando Villegaignon e, cem annos mais tarde, Nassau, renunciando heroicamente aos beneficios que nos adviriam de uma tutela francêsa ou holandêsa.

E uma nação pequenina, vivendo nos princípios do seculo $\mathrm{XVI}$ os seus ultimos dias de esplendor, conservaria durante trezentos anos a metade de um grande continente.

Houve mais.

Para que a nossa sociedade evoluisse, segundo uma diretriz constante e nitida, fazia-se mistér organizar a economia nacional, para que, satisfeitas as necessidades materiais ime- 
diatas, passassemos a preocupações superiores, entre as quais avultaria a do levantamento de uma patria.

Incalculavel o esforço a desenvolver em face da vastidão da terra e da escassez da gente; já então começava a se fazer sentir o problema da falta de braços.

Era forçoso buscar uma solução, que forrasse a metropole aos riscos, a que se veria exposta na administração da colonia, e esta solução seria unica. Não houve atender a considerações morais, sentimentais e religiosas; fundou-se a economia sôbre o trabalho servil.

Essa instituição barbara e hedionda seria a fonte de nosso progresso e prolongar-se-ia até o periodo brilhantissimo do segundo imperio; sua extinção derrubaria o trôno e acarretaria a desorganização economica em que ainda vivemos.

Não esqueçamos que foi uma solução providencial.

Buckle subordinava a organização das sociedades a quatro grandes agentes fisicos: o clima, a alimentação, o solo e o aspeto geral da natureza. Não seria necessario um estudo, ainda o mais superficial, para avaliarmos até que ponto concorreram esses quatro elementos na formação da sociedade brasileira; é fóra de dúvida que qualquer investigação nesse sentido nos levaria a resultados tão desconcertantes, que nos fariam descrêr do postulado enunciado pelo grande historiador inglês.

O certo é que, menos de três seculos depois da descoberta, revogadas as absurdas disposições do tratado de Tordesilhas, impostas pela ambição de engrandecimento facil e indolência dos reis da Espanha, está o Brasil constituido, aproximadamente, com as fronteiras atuais. E, fosse por um fenómeno de psicologia social, pelo qual o povo que se formava adquiria um "forte sentimento do proprio valor» e »uma nova conciência jurídica em colisão com as tradições da metropole», oriundos do sucesso que corôou cada protesto heroico das populações a toda "ameaça de usurpação » levada a efeito pelo inimigo estrangeiro, (1) ou fosse pela "força de coesão racial», que nos transmitiu o português, apertando sôbre o coração, durante seculos, a lingua e o espirito nacional (2), foi se manifestando desde en-

(1) Rocha Pombo - História do Brasil Ed. do Centenario, pag. 373, vol. 2.․

(2) Gustavo Barroso - Conferencia na Faculdade de Direito de São Paulo. 
tão o sentimento de uma nova patria, que receberiamos íntegra, anos mais tarde e pela conservação da qual assumiriamos solene compromisso, ao sacudir os grilhões que nos acorrentavam ao jugo português.

Ao raiar da independencia, era o Brasil, segundo a visão de Paulo Prado, - talvez pessimista, mas em cujos traços mais gerais, não podemos deixar de reconhecer a exatidão com que focalizou os carateristicos da nação por se formar, — "um corpo amórfo, de méra vida vegetativa, mantendo-se apenas pelos laços tenues da lingua e do culto ». A idéa de independência que, vagamente, repontára em algumas manifestações de caráter francamente regionalista, tendo sempre a extinguí-la em suas origens a oposição ou a indiferença das demais capitanias, só seria vencedora si trouxesse comsigo, como elemento coordenador das energias esparsas, um núcleo de atração de todas as regiões do país.

Comprendendo superiormente que seriam incapazes de sustentar o blóco nacional, os grupos de Gonçalves Ledo, dos Andradas e outros chefes do momento, talvez, destinados a representar entre nós, o drama da caudilhagem que esfacelou os grandes vice-reinos espanhóes e os entregou á mais deploravel anarquia, - arregimentaram-se em torno da figura do principe, que, com o enorme prestigio decorrente da sua dinastia, foi o ponto de convergencia de todas as provincias, assegurando assim a constituição da unidade imperial.

E, como que a antever a afirmação que modernamente faria Alberto Torres, é sob o influxo de uma "ação contínua e perseverante», através de longos anos de trabalho paciente, que se esboça o arcabouço ainda palido e indeciso de uma nacionalidade.

Em torno do segundo monarca, que reunia ao prestigio herdado de seu pai, elevado senso da moralidade e um alto descortino político, evidenciado na extrema sabedoria com que exerceu o Poder Moderador, viga mestra do mecanismo político 
adotado, avultavam as figuras de Caxias e Mauá, colaboradores da tarefa delicada que o destino lhe reservára.

O primeiro, "o mais prudente dos heróis", no elegante dizer de Euclides, teve a vida toda, incansavel a sua espada ao serviço do país, sufocando prontamente as inumeras agitações carateristicas do segundo reinado, consequência natural da política colonial desintegradora e da ação dispersiva dos fatores geograficos.

O segundo, unindo pelos laços materiais, e permitindo o intercambio comercial entre as provincias, através de extensa rêde de viação térrea de que foi o précursor e o realizador.

Três artistas.

Como sucede a todas as nações modernas, constituidas artificialmente, a nossa, em face da diversidade do sólo e da variedade das raças, foi uma obra de arte política.

Não havia cessado, entretanto, a ação fragmentadora dos fatores geograficos; sem se fazer sentir, ela permanecia surda e fatal, disfarçada na crença supersticiosa da soberania do imperante. Não poderia, porêm, a monarquia sustentar-se esporadicamente na America.

O sentimento regionalista, abafado até então pelo superior interesse nacional e encoberto pela força centripeta que trazia comsigo a realeza, explode incoercivel e arrebatador, derramando-se por todos os recantos do país. E não ha mais contê-lo em sua marcha irresistivel. Será forçoso transigir e conciliar o sentimento regional com o nacional. Esta conciliação, aparentemente impossivel, é praticamente realizavel pelo sistema federativo.

Só ele poderá satisfazer, a um tempo, aos justos anceios de uma extensa autonomia, que bem merecem algumas das unidades territoriais do Imperio, e á necessidade da conservação da patria unica, posta em perigo pelo desaparecimento previsto e inevitavel da idéa superior que tornou fativel a sua elaboração.

Esborôa-se a monarquia, e, naturalmente, sem um salto, invertem-se os papeis; já agóra, o perigo separatista está na concentração, e o constituinte republicano, mal refeito da surpreza em que o apanhou a proclamação brusca do novo regi- 
mem, poude perceber no cáos alarmante do primeiro momento, o unico caminho que nos levaria á salvação da nacionalidade. E' que á testa da nova ordem de cousas, está Rui, o grande chefe de todo o movimento liberal da Republica, óra contendo os mais exaltados, óra iluminando os menos afeiçoados á política, óra levando a fé aos mais tibios, descrentes de todas as horas, mas construindo sempre, num esforço verdadeiramente digno da energia tenaz que o acompanhou até o tumulo.

\section{III}

Um ilustre geologo inglês do seculo passado, reagindo contra a concepção antiga que via, nas grandes transformações operadas na tace do planeta, horrorosas catástrofes, estabeleceu a chamada teoria das causas atuais, segundo a qual tais pertur bações teriam ocorrido suavemente e graças á ação clemente das forças naturais.

A fantasia sutil e piedosa de Anatole France imaginou os incalculaveis beneficios que resultariam para a humanidade, si se pudesse transportar tal teoria do mundo tisico para o moral e o social. Certo, encontrariamos, então, uma fórmula ideal de harmonia entre o espirito conservador e as tendencias revolucionarias de todas as épocas.

Aquele, convencido da inutilidade das barreiras opostas ás conquistas sociais emergentes, e estas, cégamente confiantes na atividade perêne das energias naturais, não procurariam senão esforçar-se para que a evolução tatal se fizesse sem grandes colisões e no sentido mais favoravel aos interesses de cada momento. A sugestão é empolgante; desgraçadamente, é consideravel a dificuldade de introduzir a idea, e estamos ainda bem longe de afeiçoarmo-nos a ela.

Desacreditando da força de expansão irreprimivel, que possuiamos por natureza, e não resistindo aos inevitaveis contratempos do regimem presidencial, que adotáramos, lançámo-nởs á Revolução. Como sói acontecer a todas as revoluções, a nossa foi recolhendo todas as energias existentes no país, fervilhantes por estuarem-se em grandes manifestações de civismo, 
mas no dia do triunfo não poude coordenal-as todas em torno de um mesmo pensamento central definido.

Refugindo á lição da Historia, e mentindo á «tenacidade do espirito autonomico e da conciência particularista dos Estados» (1), de que foi a afir mação vitoriosa, apartou-se da nossa curta mas arraigada tradição federalista, e principiou por suprimir o principio fundamental em que assentava a unidade patria. Mas nem por isso deixou de ser um largo passo em nossa evolução. Com a força irresistivel de que vinha possuida, imprimiu-lhe violento impulso, quebrando o rítmo natural em que esta se processava. E mercê desse impulso, marchamos desabaladamente, sem poder divisar, em meio ao entrechocar das paixões divergentes, o termo da carreira em que somos arrastados.

E' possivel que caminhemos para a ordem legal que trará comsigo a organização federal sonhada, mas como tudo nos faz crêr que continuaremos no empirismo a que estamos entregues, não será de extranhar que nos vejamos muito breve em face da perspetiva angustiosa de desmembramento.

Um grande esforço coletivo, desembaraçado das peias do individualismo dissolvente e alimentado pelo fogo sagrado de um idealismo construtor, terá o condão de proporcionar ao país a diretriz de cuja falta ele se ressente.

Seremos o espectador impassivel dessa corrida dramatica?

Esperaremos que a Divina Providencia nos envie, solícita, os elementos necessarios para a obra a realizar, segundo a tése romantica lançada por Lamartine, em seguida á Revolução Francêsa de 1848 ?

\section{IV}

Afastemo-nos da primeira hipótese e permitâmo-nos fixar alguns aspetos da segunda.

Tivemos duas constituições; ambas foram envolvidas na mesma crítica superficial, - em que não resistimos á tenta-

(1) Azevedo Amaral - "Debate Academico", artigo publicado no "Diario de São Paulo" em 24-1-1932. 
ção de ver muito de retorica vazia e ôca, - de não terem correspondido ás nossas realidades.

Sem dúvida reconheceremos, na imperial, a fraseologia empolada, que nos transmitira a grandiloquencia do solitario de Genebra e que embriagava, então, os povos ocidentais eivados de romantismo. Era, efetivamente, um pacto insignificativo e estava bem longe de "exteriorizar as proprias manifestações da maneira de ser e de viver do nosso organismo político» (1).

Não seria sem grave injustiça que poderiamos dizer o mesmo do nosso estatuto de 91 .

$\mathrm{Si}$, em muitos passos, a Constituinte Republicana não soube fugir á comica terminologia da primeira República Francêsa de que óra ainda encontramos alguns resquiscios, ninguem lhe poderá contestar a lealdade com que obedeceu ao movimento espontaneo e consideravel da opinião, em favor da idéa federal; apontando em $1831 \mathrm{com}$ o projeto da Monarquia Federativa, resurgindo em $34 \mathrm{com}$ o Ato Adicional, e explodindo incontrastavel em 70 com o manifesto do Partido Republicano, foi, no dizer de Levi Carneiro, a preocupação dominante do país - retardada, dissimulada, sufocada - e, afinal, satisfeita.

Seria suficiente para redimir o legislador de outras culpas, essa obediencia céga aos imperativos da descentralização.

Reconhecem-o os maiores adversarios da nossa carta republicana.

Dentro em breve - não nos desiludamos - volveremos ao regimem da lei; já vão se delineando grandes correntes de opinião.

Avoluma-se a dos que amargurados com a dolorosa experiencia presidencialista, volvem os olhos saudosos para o velho regimem parlamentar.

Não seria fóra de proposito lembrar-lhes que não foi por acaso ou mero espirito de imitação que adotámos o sistema presidencial. Teria sido uma loucura reagir brutalmente contra a tendencia para o absolutismo, generalizada na America Latina,

(1) Finalidade atribuida ás Constituições por Alberto Torres, em "A reconstrução nacional". 
e de que, portanto, não nos seria dado escapar. Foi bem mais prudente contornarmos a dificuldade e buscarmos a solução que fosse um derivativo para os nossos pendores á autocracia.

Alêm de que, não seria agora que "o individualismo retoma o seu papel de condutor do mundo", triumfando sôbre a força brutal e céga das multidões» (1), que nós atirariamos aos braços de enormes assembléas, quasi irresponsaveis.

Outros, muito côncios de sua missão redentora, voltam-se para as constituições alemã, russa e espanhola. Pactos avançadissimos, já nos aterroriza a idéa de sua transplantação para o nosso meio. Tranquilizemo-nos, porêm. A clarividencia dos novos estadistas saberá distinguir nelas o que será adaptavel ao Brasil.

Não será impossivel que eles percebam em todas três a. sabedoria com que aplicaram e compreenderam o princípio federal, afastando-se de um igualismo que, não podendo realizar o milagre de guindar as pequenas unidades ás alturas em que vivem as demais, regula a marcha destas ultimas pelo caminhar penoso e vacilante das primeiras. Não nos furtemos, irreverentes, á crença de que igual sabedoria ha de inspirar a obra dos renovadores.

Abandonar essa última esperança seria cometer o sacrilegio de dificultar sistematicamente toda tentativa de reerguimento nacional.

Snr. Dr. Alcantara Machado: Acedendo ao nosso pedido, tivestes a imensa bondade de ser o paraninfo da nossa turma. A nossa escolha é bem mais do que uma simples atenção para com o novo Diretor da Faculdade. Representais, para nós, o professor amigo que não méde sacrificios no desempenho da sua missão fecunda.

Herdeiro das gloriosas tradições de Brasilio Machado, não desmentistes o seu renome de orador e jurista consumado. Sois,

(1) Gustavo Le Bon, citado por Gilberto Amado em "Eleição e Representação" pag. 37. 
a um tempo, a palavra clara e brifhante na cátedra, o autor consagrado da obra-prima que é a "Vida e Morte do Bandeirante", e o administrador incansavel e amigo dedicado da nossa Academia. Não fugiriamos ao dever imperioso de vos patentear a admiração e respeito com que pronunciamos o vosso nome.

Dentro de alguns instantes, deixaremos o enorme casarão. Quizéramos, fosseis vós o depositario da nossa gratidão para com todos os nossos mestres. Já não poderiamos fazê-lo. Depois de uma vida atribulada de trabalho e sofrimentos, cumprindo abnegadamente o seu dever, deixou-nos o professor Otavio Mendes. Arrefece o nosso entusiasmo a lembrança dessa perda e a de dois colegas a quem não foi dado suportar a cruz que arrastamos penosamente.

Mais alguns momentos e deveremos partir para a luta. Do topo de nossa vida academica procuramos divisar o horizonte que ha de circunscrever a nossa ação. Temerosos, deante da imensidão do deserto que se nos depára, e vacilantes de comoção, estacamos atonitos. Desfalecemos por um momento e esvái-se o nosso entusiasmo. Mas, logo, a certeza da eficacia dos ensinamentos recebidos nos restitúi o ânimo que óra assumimos. Ouçamos as palavras do nosso paraninfo; elas serão, por entre as incertezas da hora que passa, o guia seguro que nos mostrará o verdadeiro caminho a seguir, e a bandeira em torno da qual nos arregimentaremos em nosso batalhar perêne pela vitoria dos princípios que esta Casa nos ensinou a respeitar. 